\title{
La transparencia en la Unión Europea
}

\section{MEI \\ II, vol. 3 \\ $\mathrm{n}^{0} 5$}

\author{
Mario Francisco Quirós Soro \\ Universitat de València
}

Recibido el 19-09-2012

Aceptado en 18-12-2012

\begin{abstract}
Resumen
Este estudio versa sobre la formación histórica y vigencia del marco jurídico europeo, en materia de transparencia. Se centra en el derecho de la Unión Europea, por constituir un referente básico de los Estados miembros, en cuanto a la influencia en los ordenamientos jurídicos internos de los mismos. El estudio comprende los Tratados y el derecho derivado, junto a otros actos relacionados con la materia que nos ocupa, durante el periodo de vigencia de cada Tratado, con referencias a la jurisprudencia comunitaria. Además, los estudios sobre la Carta de los Derechos Fundamentales de la Unión Europea y los Códigos de Buena Conducta Administrativa, efectuados por separado, a efectos de mayor claridad expositiva. Un apartado describe los medios de acceso existentes en Internet, a los documentos de las instituciones comunitarias. Por otra parte, se estudia también la labor del Consejo de Europa en materia de transparencia.
\end{abstract}

\section{Palabras clave \\ Transparencia; Documentos; Tratado; Reglamento; Consejo de la Unión Europa; Comisión; Parlamento Europeo; Defensor del Pueblo Europeo. \\ Transparency in the European Union \\ Abstract \\ This study deals with the historical formation and validity of the European legal framework, in field of transparency. It focuses on the right of the European Union law, as it constitutes a basic reference for members States, in terms of the influence of their internal legal systems. The study includes the Treaties and secondary legislation, along with other events related to the subject at hand, during the term of each Agreement, with references to case law. In addition, studies on the Charter of fundamental Rights of the European Union and the Codes of Good Administrative Behaviour, made separately for the purpose of expository clarity. A media section describes exiting internet access to documents of the EU institutions. Moreover, also analyzed is the work of the Council of Europe in terms of transparency.}

\section{Keywords}

Transparency; Documents; Treaty; Council Regulation; Council of The European Union; Commission; European Parliament; European Ombudsman.

\section{Introducción}

En una sociedad democrática, el derecho a la información constituye un presupuesto de la transparencia, la cual refuerza la confianza de la ciudadanía en los gobiernos y en las administraciones públicas ${ }^{1}$.

El derecho comunitario europeo está estructurado en dos bloques: por un lado, el derecho primario u originario, constituido por los Tratados constitutivos de las Comunidades Europeas y sus modificaciones. Por otro, el derecho derivado integrado por los instrumentos de las instituciones europeas ${ }^{2}$ : reglamentos, directivas y decisiones, de carácter 
vinculante ${ }^{3}$, y recomendaciones y dictámenes, de carácter no vinculante. Además, las instituciones emiten otros actos, como acuerdos, declaraciones, comunicaciones y conclusiones.

\section{Los Tratados constitutivos de las Comunidades Europeas}

Como indica Cerrillo, el Tratado constitutivo de la Comunidad Económica Europea, el Tratado constitutivo de la Comunidad Europea de la Energía Atómica, ambos de 1957 y el Tratado constitutivo de la Comunidad Europea del Carbón y del Acero de 1951, no hicieron "ninguna referencia directa en ninguno de sus artículos a la transparencia administrativa," si bien expone que "de todas formas sí que se pueden encontrar algunas normas que tienen cierta incidencia sobre la transparencia” (Cerrillo i Martínez, 1998, p. 37). Cita una serie de preceptos, de entre los que destacan los contenidos en el Tratado constitutivo de la Comunidad Económica Europea ${ }^{4}$. Por un lado, los relativos a la motivación de reglamentos, directivas y decisiones del Consejo y de la Comisión, (Art. 190), si bien "no podemos deducir que se establezca un verdadero principio de transparencia, ya que su dictado sólo se circunscribe a normas vinculantes.” No obstante y como señala, en el artículo 5 del Tratado constitutivo de la Comunidad Europea del Carbón y del Acero, "sí podemos encontrar este principio" (Cerrillo i Martínez, 1998, pp. 38-39), cuando determina las actividades dirigidas al cumplimiento de la misión de la Comunidad ${ }^{5}$.

Por otro lado, volviendo al Tratado constitutivo de la Comunidad Económica Europea, la publicación de documentos de la Asamblea (Art. 142) y de reglamentos y notificación de directivas y decisiones (Art. 191), así como la publicación por la Comisión, de un informe sobre las actividades de la Comunidad (Art. 156) y la facultad de aquélla de poder recibir todo tipo de información, en el ejercicio de sus funciones, no obstante dentro de los límites establecidos por el Consejo y a excepción de la información de los Estados miembros, cuya divulgación estuviese amparada por el secreto profesional o pusiera en riesgo su seguridad (Arts. 213, 214 y 223 1.a) ${ }^{6}$.

En este periodo destacan por un lado, el Reglamento del Consejo de 1 de febrero de 1983, sobre apertura al público de los archivos históricos de la Comunidad Económica Europea y de la Comunidad Europea de la Energía Atómica, así como la Decisión de 8 de febrero del mismo año, sobre apertura de los archivos históricos pertenecientes a la Comunidad Económica del Carbón y del Acero 7 .

Por otro lado, la aprobación de la Directiva del Consejo de 7 de junio de 1990, sobre libertad de acceso a la información medioambiental ${ }^{8}$. En base a los principios y objetivos de programas de la materia, el Consejo estimó que el acceso a dicha información, mejoraría la protección del medio ambiente. Su objeto era garantizar el acceso y difusión de dicha información en poder de las autoridades públicas, al tiempo

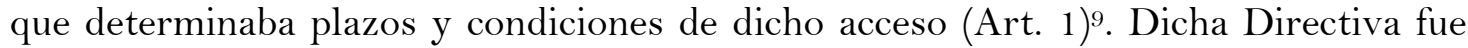
traspuesta al ordenamiento jurídico español, en virtud de la Ley 38/1995 de 12 de diciembre, sobre el derecho de acceso a la información en materia de medio ambiente ${ }^{10}$. 


\section{El Tratado de Maastricht}

El 7 de febrero de 1992 tuvo lugar en Maastricht la adopción del Tratado de la Unión Europea, el cual entró en vigor el 1 de noviembre de 1993 ${ }^{11}$. Para Guichot, con ello "se trató de salvar las críticas al mercantilismo y opacidad de la construcción comunitaria” (Guichot, 2011, p. 78). Modifica el Tratado constitutivo de la Comunidad Económica Europea, que pasa a denominarse Comunidad Europea y declara que "las decisiones serán tomadas de la forma más próxima posible a los ciudadanos" (Art. A) ${ }^{12}$. Destaca sin duda, la Declaración $n^{\circ} 17$ sobre el derecho de acceso a la información del proceso de decisión de las instituciones europeas, aneja al Acta final del Tratado de la Unión Europea, como medio de impulsar mediante la adecuada transparencia, la democracia institucional y obtener la confianza de la ciudadanía en la administración. Al mismo tiempo se solicitaba de la Comisión, un informe sobre medidas destinadas a la mejora del acceso del público a la documentación en manos de las instituciones. Como señala Cerrillo, al carecer de aplicación directa se trataba de "una invitación a actuar de una determinada manera o ser puramente una declaración de intenciones." Cita a Constantinesco, para quien "se ha pretendido dar eco al déficit democrático de la Unión Europea" (Cerrillo i Martínez, 1998, pp. 75-76).

Por otra parte, tras el cierre del ejercicio anual, el Tribunal de Cuentas debía redactar un informe, el cual sería publicado en el Diario Oficial de las Comunidades Europeas (Art. 188C 4). Asimismo, el Tratado dispuso la publicación de los reglamentos del Consejo y de la Comisión, así como las directivas de dichas Instituciones, que tuviesen como destinatarios a todos los Estados miembros (Art. 191.2).

Los Consejos Europeos celebrados en Birmingham, Edimburgo y Copenhague ${ }^{13}$, establecieron las líneas de actuación, al objeto de lograr una Comunidad más transparente. Por su parte, la Comisión dirigió su labor al cumplimiento del mandato contenido en la Declaración de Maastricht. Tres Comunicaciones recogieron las medidas adoptadas y los resultados obtenidos ${ }^{14}$.

Los primeros trabajos dieron como resultado la aprobación por el Consejo de su Reglamento interno, el cual fue objeto de posteriores reformas. Contiene las disposiciones relativas a la transparencia aplicables al funcionamiento de la Institución ${ }^{15}$.

El 6 de diciembre de 1993, el Consejo y la Comisión adoptaron un Código de Conducta sobre acceso del público a sus documentos ${ }^{16}$. Su finalidad era concertar los principios de acceso a los documentos de dichas Instituciones, si bien carecía de efectividad jurídica. Como señala Guichot, era tan "sólo una expresión de coordinación voluntaria interinstitucional, pero constituía la base para su posterior positivación y desarrollo por cada Institución” (Guichot, 2011, p. 80). Declaraba como principio general, el mayor acceso posible a sus documentos. Entendía por tales a todo escrito que contuviese datos con independencia del soporte en poder de dichas Instituciones. Disponía las normas sobre iniciación, tramitación y resolución de solicitudes, modos de acceso a los documentos, necesidad de motivar las resoluciones denegatorias del acceso, recursos frente a las mismas ${ }^{17}$ y excepciones al acceso ${ }^{18}$ : protección de intereses públicos, de las personas y de la intimidad, secretos en materia 
comercial e industrial, intereses financieros de la Comunidad, confidencialidad solicitada por las personas físicas y jurídicas o que requiera la legislación del Estado miembro, que hubiesen facilitado datos contenidos en los documentos, así como en los casos de protección del secreto de las deliberaciones de las Instituciones.

Tras la aprobación del Código de Conducta y a fin de llevar a cabo su puesta en práctica, una Decisión del Consejo de 20 de diciembre de $1993^{19}$ y otra de la Comisión de 8 de febrero de $1994^{20}$, sobre el acceso del público a sus documentos, recogieron los principios contenidos en el referido Código. Posteriormente, otras instituciones, órganos y organismos comunitarios, fueron adoptando disposiciones de acceso en relación con sus documentos ${ }^{21}$.

Por su parte en junio de 1996, el Defensor del Pueblo Europeo inició una investigación referida al acceso del público a los documentos de instituciones y órganos de la Comunidad, distintos al Consejo y a la Comisión, que como hemos visto, poseían sus propias normas (Defensor del Pueblo Europeo, 1996, pp. 83-90). Los motivos fueron la carencia de formación del personal de instituciones y órganos comunitarios, sobre el tratamiento de solicitudes de documentos y el retraso en su publicación. La investigación fue concluida en diciembre de aquel año, en virtud de Decisión de 20 de diciembre, en que puso de manifiesto que la ausencia de normas sobre acceso del público a los documentos ${ }^{22}$, podía constituir un caso de mala administración. Estimaba que la buena administración requería que la totalidad de los órganos e instituciones comunitarios, tuviesen en cuenta el compromiso de la Unión Europea establecido en la citada Declaración $\mathrm{n}^{0} 17$, por un mayor grado de transparencia. Por tanto, formuló proyectos de recomendación a instituciones y organismos, a fin de que adoptasen medidas sobre acceso del público a los documentos.

Un informe especial contiene las respuestas de las instituciones y órganos a los proyectos de recomendación, de cuyo análisis dedujo que la mayoría de las normas aprobadas, habían tomado como referencia las Decisiones del Consejo y de la Comisión, a las que me he referido. No obstante, existía una limitación de las normas comunitarias sobre acceso, respecto de las adoptadas en algunos Estados miembros. Además carecían del derecho de acceso a documentos que estuviesen en poder de un órgano, pero tuvieren su origen en otro distinto, así como del establecimiento de registros de documentos, que al tiempo que facilitarían el derecho de acceso, fomentarían la buena administración y prevendrían la pérdida de documentos.

El Defensor del Pueblo recomendaba al Parlamento Europeo, que examinase las normas de acceso, a fin de verificar si garantizaban el grado de transparencia exigido por la Unión Europea. Asimismo, que solicitase a las instituciones y órganos que no lo hubieren efectuado, a poner sus documentos a disposición del público, en las lenguas oficiales de la Comunidad y que publicasen sus normas de forma adecuada ${ }^{23}$.

Por otra parte, en la resolución de 16 de julio de 1998 del Parlamento Europeo sobre el anterior informe ${ }^{24}$, sugirió entre otros aspectos, la posibilidad de poder entablarse recursos ante el Tribunal de Primera Instancia o el Tribunal de Justicia, en los casos de denegación de solicitudes de acceso a documentos (Apdo. 14).

Entre tanto, la Secretaría General del Consejo había promovido la creación de un 
registro público "fiable y exhaustivo," de los documentos de la Institución, que mejorase el acceso del público a los mismos. Contendría los documentos no clasificados como reservados y su acceso se efectuaría a través de Internet ${ }^{25}$. Esta iniciativa fue acogida por el Parlamento, que sugirió su formación por las restantes instituciones y organismos comunitarios (Apdo. 18)26.

Con vistas a reforzar la transparencia de la legislación comunitaria, un Acuerdo interinstitucional de 22 de diciembre de 1998, entre el Parlamento, el Consejo y la Comisión ${ }^{27}$, dispuso las directrices a observar en la redacción de los textos normativos. Entre los principios generales, destacan la claridad, sencillez, precisión y concisión en la formulación de los actos legislativos, redacción con arreglo al tipo de acto y a los destinatarios a que fuesen dirigidos, empleo de terminología coherente entre las disposiciones de un mismo acto y entre otros actos comunitarios. Tanto el Parlamento como la Comisión, estimaron que el acto legislativo comunitario "debería ser comprensible por sí mismo." Se mostraron contrarios a la adopción de declaraciones interpretativas. Además, el Consejo consideró que la mejora de la transparencia del proceso de decisión, podría lograrse mediante la publicación de las exposiciones de motivos de sus propuestas legislativas.

\section{El Tratado de Amsterdam}

El 2 de octubre de 1997 fue adoptado en Amsterdam un nuevo Tratado, que entró en vigor el 1 de mayo de 1999. Modifica el Tratado de la Unión Europea y los constitutivos de las Comunidades Europeas ${ }^{28}$. El primero declara el principio de apertura en la forma de adopción de decisiones, al introducir la expresión "más abierta" (Art. 1)29. El Tratado de la Comunidad Europea, declara expresamente el derecho de los ciudadanos de la Unión Europea y de las personas físicas o jurídicas residentes en un Estado miembro, al acceso a la documentación del Parlamento, Consejo y de la Comisión. Al Consejo se le encomendaba la labor de determinar los principios y límites al ejercicio de dicho derecho, por motivos de interés público o privado. Cada institución debía incluir en propio reglamento interno, las normas

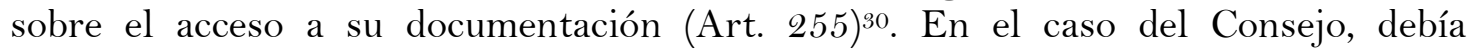
especificar los casos en que actuaba como legislador, a fin de facilitar mayor acceso a los documentos ${ }^{31}$, de tal modo que haría público los resultados de las votaciones, sus explicaciones y las declaraciones del acta (Art. 207.3) ${ }^{32}$.

En los casos en que fuesen denegadas las solicitudes de acceso a la documentación, el interesado podía recurrir ante el Defensor del Pueblo Europeo o ante el Tribunal de Justicia (Arts. 195 y 230).

El Tratado de la Unión Europea declaró la aplicación del derecho de acceso a los documentos relativos a la política exterior y de seguridad común, así como a los referentes a la cooperación policial y judicial en materia penal (Arts. 28.1 y 41.1).

Por otra parte, en la Declaración $\mathrm{n}^{\mathrm{o}} 35$ aneja al Acta final del Tratado, la Conferencia introdujo una excepción, en virtud de la cual, un Estado miembro podría solicitar a la Comisión o al Consejo, que no comunicase a terceros, "un documento originario de dicho Estado sin su consentimiento previo." Otra Declaración, en este caso la $n^{\circ} 41$, estimaba que cuando el Parlamento, el Consejo y la Comisión, actuasen a título del Tratado constitutivo de la Comunidad Europea del Carbón y del Acero y 
del Tratado constitutivo de la Comunidad Europea de la Energía Atómica, debían inspirarse en las "disposiciones en materia de transparencia, de acceso a los documentos", vigentes en el Tratado constitutivo de la Comunidad Europea. Por último, en la Declaración $n^{\circ} 39$, la Conferencia abogaba por el establecimiento por parte del Parlamento, el Consejo y la Comisión, de directrices para la mejora de calidad en la redacción de la legislación comunitaria, para su comprensión por la opinión pública, así como la codificación de los textos legislativos, a fin de facilitar su accesibilidad.

En este periodo destaca el Reglamento 1049/2001, sobre acceso del público a los documentos del Parlamento, del Consejo y de la Comisión ${ }^{33}$, con el que según Cotino, "se ha apostado por una visión muy expansiva y aperturista de este derecho." (Cotino Hueso, 2002, p. 10). Desarrolla el artículo 255 del Tratado. Establece los principios generales de acceso a la documentación institucional. Destaca la apertura como garantía de la participación de los ciudadanos en la toma de decisiones, al tiempo que refuerza la democracia y el respeto de los derechos fundamentales de la Unión Europea. Como expresa el preámbulo, su objeto consiste en garantizar en forma amplia, "el derecho de acceso del público a los documentos y determinar los principios generales y los límites que han de regularlo," los cuales se extienden a las agencias creadas por las instituciones comunitarias. Destaca la importancia de incrementar el acceso documental, cuando las instituciones actúen con capacidad legislativa, aún en el caso de delegación de poderes, así como de proporcionar el acceso directo a dichos documentos. Por otra parte, la norma amplía el derecho de acceso a los documentos recibidos por las instituciones, con arreglo a la excepción establecida en la citada Declaración $n^{\circ} 35$. Además, declara la sujeción al Reglamento de las normas sobre acceso a documentos de las instituciones, las cuales han de permitir el acceso a un registro documental.

Son beneficiarios del derecho de acceso, los ciudadanos de la Unión y las personas físicas o jurídicas residentes o con domicilio social en un Estado miembro. No obstante y con carácter potestativo, el derecho puede concederse a personas físicas y jurídicas que no residan ni posean su domicilio social en un Estado miembro. El ámbito de aplicación de la norma comprende todo tipo de documentos en manos de una institución (Art. 2 .1 .2 2 y .3).

La norma conceptúa dos categorías de documentos: los que podemos calificar de comunes $^{34}$ y los sensibles ${ }^{35}$. Asimismo delimita las excepciones al acceso de documentos por diversos tipos de intereses. De un lado por motivos de interés público, los relacionados con la seguridad, la defensa y asuntos militares, relaciones internacionales, políticas económica, financiera y monetaria; y por interés particular: intimidad e integridad personal, intereses comerciales y propiedad intelectual. De otro, aquellos que pudiesen perjudicar a procedimientos judiciales, asesoramiento jurídico y actividades inspectoras, de investigación y auditorías. Asimismo, documentos de uso interno relativos a asuntos pendientes de resolución por la institución, o que contuviesen opiniones de uso interno derivadas de deliberaciones o consultas previas, "incluso después de adoptada la decisión." En estos casos, la excepción queda sujeta a que la divulgación del documento, perjudique el proceso de toma de decisiones de la institución de que se tratase, salvo que dicha divulgación revistiese un interés público superior. 
Tratándose de documentos de terceros, la institución debe consultarles a efectos de aplicación de las excepciones. De otra parte, si un Estado miembro lo estima oportuno, puede solicitar de una institución que no permita sin previo consentimiento, el acceso a un documento originado en dicho Estado, de acuerdo con la Declaración $n^{\circ} 35$ aneja al Acta final del tratado.

Cabe la posibilidad de aplicación parcial de las excepciones, lo que motiva la difusión del resto del documento. En todo caso, las excepciones surten efectos mientras esté justificada la protección, en relación con el contenido de los documentos ${ }^{36}$. No obstante, el periodo de aplicación no puede superar los treinta años, salvo que se trate de excepciones por motivos de intimidad, intereses comerciales o documentos sensibles, en cuyo caso pueden seguir aplicándose con posterioridad a dicho periodo, si se considerase necesario.

En los casos en que un Estado miembro reciba la solicitud de documentos que obren en su poder y sean originarios de las instituciones, antes de adoptar la resolución, deberá consultar con la institución pertinente, a fin de no malograr los objetivos del Reglamento, salvo que resulte clara la estimación o desestimación de la solicitud de acceso. En otro caso, el Estado miembro puede remitir la solicitud a la institución de que se trate (Arts. 4 y 5 ).

Las solicitudes se efectúan en forma escrita, incluida la red electrónica y en cualquiera de las lenguas oficiales, de modo que, como indica Guichot, "se acoge un principio antiformalista" (Guichot, 2011, p. 230). Deben redactarse de forma clara y precisa, de modo que permita la identificación del documento solicitado, no siendo necesario señalar la justificación de la solicitud. En los casos de imprecisión de solicitudes, las instituciones prestan ayudan a los solicitantes, mediante las informaciones sobre el empleo de los medios en materia de acceso.

La norma establece dos tipos de solicitudes de acceso a los documentos: iniciales y confirmatorias. El periodo de resolución de las solicitudes iniciales es de quince días, ampliable por otro de igual duración, por motivos de solicitud de gran número de documentos o carácter extensivo de los mismos. De concederse el acceso, deberá efectuarse en el plazo de quince días. Si el sentido de la resolución fuese negativo, total o parcialmente, debe motivarse, al tiempo que informar al solicitante de la posibilidad de presentar en el plazo de quince días, una solicitud confirmatoria, al fin de que la institución reconsidere el sentido de la resolución. En caso de ausencia de respuesta de la institución, el silencio administrativo se interpreta como negativo y da derecho a la presentación de la solicitud confirmatoria.

En cuanto a las solicitudes confirmatorias, el plazo de resolución es idéntico al establecido para las solicitudes iniciales. Si de forma total o parcial el acceso fuese denegado, además de indicarse el motivo, deberá informarse al solicitante de los recursos disponibles frente a la denegación del acceso: judicial contra la institución de que se trate y/o de reclamación ante el Defensor del Pueblo ${ }^{37}$. Respecto al silencio administrativo, también se interpreta como negativo y da derecho a la interposición de los medios de impugnación señalados.

Los documentos sensibles se incluyen en un registro. Su tramitación se encuentra en manos del personal autorizado a conocer su contenido, siendo público el régimen 
normativo establecido por las instituciones, para este tipo de documentos. En caso de denegación de acceso a un documento sensible, deberá motivarse de modo que no afecte a los intereses protegidos. Por otra parte, el Consejo y la Comisión deben informar al Parlamento sobre este tipo de documentos, con arreglo a los acuerdos celebrados entre las instituciones (Arts. 6 a 9).

El acceso a los documentos solicitados, puede efectuarse mediante consulta en el lugar donde se encuentren, o mediante entrega de copia. Si el documento hubiese sido divulgado por la institución y su accesibilidad resultase fácil, bastará con indicar la forma de obtención. Además, la norma contempla el acceso directo a los documentos, en particular los relacionados con la adopción de actos jurídicos vinculantes para los Estados miembros, así como a los relativos a la elaboración de políticas y estrategias. El acceso se efectúa a través de medios electrónicos o de un registro existente en cada institución, la cual debe asignar un número de referencia a cada documento ${ }^{38}$. En caso contrario, el registro debe indicar la localización de los documentos (Arts. 10 a 12).

El Reglamento dispuso la publicación en el Diario Oficial de un conjunto de documentos, que Guichot clasifica en "relacionados con la actividad prelegislativa y con la actividad convencional de la Comunidad y de los Estados en el marco comunitario" 39 y aquellos otros "atinentes a actos programáticos o no vinculantes" (Guichot, 2011, p. 263) ${ }^{40}$. Con carácter potestativo, las instituciones pueden establecer en su reglamento interno, otros documentos a publicar en el Diario oficial. A fin de promover la difusión de los derechos reconocidos en la norma, las instituciones vienen obligadas a informar al público del contenido de aquéllos, incluso mediante la cooperación de los Estados miembros (Artículos 13 y 14).

Por otro lado se ha dispuesto el establecimiento por parte de las instituciones, de buenas prácticas administrativas que faciliten el derecho de acceso, similares a las contenidas en los Códigos de Buena Conducta Administrativa. Dicha labor se encomienda a un Comité interinstitucional en que además de examinar el ideal de las prácticas, se encargan de resolver los conflictos que puedan suscitarse (Art. 15). El Comité estaría integrado, como señala Guichot, por "representantes políticos de las tres instituciones" (Guichot, 2011, p. 253).

A efectos informativos, la norma ha previsto la publicación anual de los casos en que el acceso fuese denegado, con indicación de las causas. Además, el número de documentos sensibles no incluidos en el registro. A fin de alcanzar la aplicación efectiva del Reglamento, las instituciones deben efectuar las modificaciones pertinentes en sus reglamentos internos (Arts. 17 y 18). De ahí que como indica Tomás, "el Reglamento se configura como patrón en la materia" (Tomás Mallén, 2004, p. 88). Así lo hicieron entre otros, el Consejo, el Parlamento y la Comisión ${ }^{41}$.

El deseo de extender la aplicación del citado Reglamento, llevó a las tres instituciones a acordar, conforme a su preámbulo, que las agencias comunitarias debían disponer de normas de acceso a sus documentos, basadas en los principios establecidos en el Reglamento, con el ruego de que lo adoptasen también otras instituciones y organismos ${ }^{42}$. Otras disposiciones sobre acceso del público a los documentos, fueron revisadas y actualizadas con arreglo a las medidas prescritas en el Reglamento ${ }^{43}$. 
En junio de 2002 fue celebrado en Sevilla un Consejo Europeo. Las conclusiones pusieron de manifiesto el avance en favor de la transparencia, al efectuar la apertura al público de las sesiones del Consejo, cuando actuase en codecisión con el Parlamento Europeo ${ }^{44}$.

\section{El Tratado de Niza}

El 26 de febrero de 2001 tuvo lugar la firma del Tratado de Niza, el cual entró en vigor el 1 de febrero de $2003^{45}$. Extendió los actos de protección del tratamiento y circulación de los datos personales, a las instituciones y organismos comunitarios (Art. 286 del Tratado de la Comunidad Europea).

Al objeto de aproximar aún más la Unión Europea, un Acuerdo administrativo entre la Comisión y el Reino de España de 25 de marzo de 2006, dispuso el derecho de los ciudadanos y personas físicas y jurídicas, cuya residencia o sede radicase en España, a dirigirse a la Comisión en cualquiera de las lenguas oficiales de dicho Estado $^{46}$.

En junio del mismo año se celebró en Bruselas un Consejo Europeo, cuyas conclusiones recogieron el cometido de llevar a cabo una política global sobre transparencia. Constan de un conjunto de medidas, dirigidas a alcanzar mayor participación de los ciudadanos en la labor de la Unión ${ }^{47}$.

\section{El Tratado Constitucional}

En 2004 tuvo lugar el Tratado sobre la Constitución europea ${ }^{48}$, cuyo fracaso devino al no recibir suficiente respaldo por los Estados miembros. En relación con la transparencia de las instituciones y el derecho a la información, contenía importantes disposiciones. En primer lugar, los principios de democracia representativa y participativa. Por el primero, los ciudadanos se encontraban representados en el Parlamento Europeo, a los que se les reconocía el derecho a la participación en la vida democrática de la Unión, en que las decisiones serían adoptadas de forma abierta y próxima a los ciudadanos. El principio de democracia participativa disponía que las instituciones debían otorgar a los ciudadanos y sus asociaciones, la posibilidad de expresar de forma pública sus opiniones, mantener un diálogo abierto, transparente y regular con la asociaciones y la sociedad civil, al tiempo que como garantía de transparencia de las acciones de la Unión, la Comisión habría de mantener consultas con los interesados (Arts. I-46 .2 y .3 y $\mathrm{I}-47.1 .2$ y .3 ). Insiste en el respeto al principio de apertura en la actuación de instituciones, órganos y organismos de la Unión, al tiempo que declara la publicidad de las sesiones del Parlamento Europeo y las del Consejo, en que se tratase y votase sobre proyectos de actos legislativos. Respecto del derecho de acceso a documentos, ampliaba su ámbito de aplicación, puesto que además de los relativos a las instituciones, el derecho alcanzaba a la documentación existente en otros órganos u organismos de la Unión, con independencia de su soporte. Sus reglamentos internos debían adaptarse a las disposiciones particulares de acceso a sus documentos (Art. I-50).

En cuanto al Tribunal de Justicia, el Banco Central Europeo y el Banco Europeo de Inversiones, el derecho de acceso se encontraba limitado, pues comprendía los casos en que aquéllos ejerciesen funciones administrativas (Art. III-399 .1). El Tratado 
dispuso la apertura de la administración europea, como principio básico en el cumplimiento de las funciones de las instituciones, órganos y organismos comunitarios, como garantía de la transparencia en sus actuaciones. El Parlamento y el Consejo debían procurar la publicación de documentos sobre procedimientos legislativos. (Arts. III-398 y III-399 .2).

La segunda parte del Tratado Constitucional, contiene la Carta de los Derechos Fundamentales de la Unión, que incluye como tales, la protección y acceso a expedientes y datos de carácter personal, libertad de recepción y de comunicación de informaciones, a la buena administración y acceso a los documentos de las instituciones, órganos y organismos de la Unión Europea (Arts. II-68, II-71, II-101 y II-102).

\section{El Tratado de Lisboa}

El 13 de diciembre de 2007 tuvo lugar la adopción de un nuevo Tratado en Lisboa, en vigor desde el 1 de diciembre de 2009 ${ }^{49}$. Incorpora al Tratado de la Unión Europea, los principios de democracia representativa y participativa y protección de datos personales, (Arts. 10, 11 y 39) tal como establecía el Tratado Constitucional. Por otra parte declara la publicidad de las reuniones del Consejo sobre actos legislativos (Art. 16 .8). El Tratado de la Comunidad Europea, pasa a denominarse Tratado de Funcionamiento de la Unión Europea, al que se incorporan el principio de apertura y la transparencia en la actuación de instituciones, órganos y organismos de la Unión, el derecho de acceso a los documentos, protección de datos de carácter personal, tratamiento y circulación de los mismos (Arts. 15, 16 y 298.1), contenidos en el referido Tratado Constitucional. De este modo, el derecho de acceso comprende, además de los documentos de las instituciones, el de órganos y organismos de la Unión (Art. 15 .3).

En 2009, una Decisión de 1 de diciembre del Consejo aprobaba su Reglamento interno $^{50}$. Su anexo II contiene las disposiciones específicas aplicables al acceso del público a los documentos del Consejo, cuya base lo constituye el Reglamento 1049/2001. Asimismo, el Consejo Europeo también aprobó su reglamento interno ${ }^{51}$.

\section{La Carta de los Derechos Fundamentales de la Unión Europea}

La Carta de los Derechos Fundamentales fue adoptada en Niza en 2000 ${ }^{52}$. Contiene entre otros, los derechos de recepción de información, protección y acceso a datos y expedientes de carácter personal, a la buena administración, obligación de la administración de motivar sus decisiones y acceso a los documentos de las instituciones europeas (Arts. 8, 11, 41 y 42). Como vimos, en 2004 formó parte del Tratado constitucional. En 2007 el texto fue reformado y de nuevo proclamado ${ }^{53}$. En cuanto al derecho de acceso, además de los documentos de las instituciones, amplió el ámbito del ejercicio de dicho derecho, a los órganos y organismos de la Unión, tal y como estaba previsto en el Tratado constitucional (Art. 42, en relación con el art. II102 del Tratado constitucional y el 15.3 del Tratado de Funcionamiento de la Unión Europea). El Tratado de la Unión Europea concede a la Carta el mismo valor jurídico que los Tratados (Art. 6.1). 


\section{Los Códigos de Conducta Administrativa}

La iniciativa de constituir un Código de Conducta Administrativa, aplicable a las instituciones y organismos comunitarios, surgió de la mano de Roy Perry, ponente del informe anual de la actividad de la Comisión de Peticiones, correspondiente al ejercicio 1996-1997. El Parlamento, en virtud de propuesta de resolución, solicitó de la Comisión la redacción de normas "relativas al servicio que el ciudadano europeo puede esperar de la Comisión” (Apdo. 12), basadas en unos principios fundamentales de entre los que destacan por un lado, su control y la publicación de datos estadísticos. Por otro, el derecho de los ciudadanos a que se les atendiese con corrección y a que se contestase a sus escritos en un plazo reglamentario ${ }^{54}$. Para Tomás, "es la primera vez que vemos utilizado el término derecho, en el ámbito de la buena administración -lo que no deja de tener cierta relevancia- y, sobre todo, nace la idea de los futuros códigos de buena conducta administrativa." (Tomás Mallén, 2004, p. 76).

En sucesivos informes anuales, el Defensor del Pueblo Europeo, había puesto de manifiesto la necesaria adopción de un Código de buena conducta, que mejorase la actividad de las instituciones, al tiempo que aproximase la relación entre éstas y las personas. En resolución de 16 de julio de 1998, el Parlamento estimó que dicha propuesta debía "verse en estrecha relación con la mayor transparencia y la mejora del acceso público a los documentos" ${ }^{55}$. Posteriormente, otra resolución de 15 de abril de 1999, sobre el informe de las actividades del Defensor del Pueblo durante 1998, destacaba la importancia de la redacción del Código, el cual debía ser accesible para los ciudadanos, mediante su publicación en el Diario Oficial ${ }^{56}$.

En noviembre de 1998, el Defensor del Pueblo inició una investigación sobre la existencia y el acceso público a un Código de Buena Conducta Administrativa, en las instituciones y órganos comunitarios, cuyo informe especial tuvo lugar en abril de 2000. La iniciativa tuvo lugar con motivo del creciente número de reclamaciones, presentadas ante la Institución por motivos de mala administración ${ }^{57}$ de instituciones y órganos comunitarios, hecho que el Parlamento interpretaría como "la preocupación de los ciudadanos por una administración más eficaz y transparente” 58 .

Con arreglo al Código de Conducta de la Comisión sobre acceso del público a los documentos, visto más atrás y al principio de apertura introducido por el Tratado de Amsterdam, en julio de 1999 el Defensor del Pueblo Europeo presentó a las instituciones, órganos y agencias comunitarias, un proyecto de recomendación y adjunto a éste, otro sobre un Código de Buena Conducta Administrativa ${ }^{59}$.

$\mathrm{Su}$ objeto era aproximar la administración a los ciudadanos. El proyecto contiene los principios básicos que los funcionarios debían observar en su trato con el público. Consistían entre otros, en la adopción de decisiones en un plazo "razonable" y en todo caso no superior a dos meses, además de motivar las decisiones de las instituciones desfavorables a los derechos de las personas privadas, en cuyo caso debía indicarse los medios de recurso frente a dichas decisiones (Arts. 17, 18 y 19). De otro lado, en el respeto de la legislación en materia de protección y circulación de datos personales y en facilitar el acceso a los documentos solicitados, con arreglo a la decisión adoptada por la institución (Arts. 21 y 23). Por otra parte, debía procederse al mantenimiento de archivos de documentos, a la publicidad del Código y a la reclamación ante el 
Defensor del Pueblo Europeo, ante el incumplimiento por los funcionarios de los principios recogidos en el Código (Arts. 24 a 26).

Tras el análisis resultante de la investigación, el Defensor del Pueblo, al objeto de uniformar la aplicación de las normas de buena conducta administrativa, en instituciones y órganos comunitarios en sus relaciones con el público, recomendó al Parlamento la aprobación en forma de Reglamento, de una norma destinada a tal fin.

Como dije, la Carta de los Derechos Fundamentales de 2000, incluyó como tal al derecho de los ciudadanos a la buena administración, el cual se mantuvo en los textos de 2007 y 2010. Consiste en el deber de las instituciones y órganos comunitarios, de tratar los asuntos de forma imparcial y equitativa, dentro de un plazo razonable. Comprende entre otros aspectos, la obligación de la administración de motivar sus decisiones (Art. 41).

En 2001, una resolución de 6 de septiembre del Parlamento Europeo, aprobaba el Código Europeo de Buena Conducta Administrativa, no sin antes introducir algunas modificaciones al proyecto del Defensor del Pueblo60. Para Tomás, dicha aprobación "marca un punto de inflexión y de regeneración de los Códigos de todos los organismos comunitarios” (Tomás Mallén, 2004, p. 272). Su base es el derecho a la buena administración por parte de instituciones y órganos de la Unión Europea y constituye el referente en la actuación del personal al servicio de dichas instituciones y organismos. El Código constituye un elemento de control en manos del Defensor del Pueblo, relativa a la mala administración por parte de instituciones y organismos comunitarios.

En relación con las solicitudes de documentos, dispuso que los funcionarios se ajustasen a la norma de la institución de que se tratase y al Reglamento 1049/2001 (Art. 23). No obstante, con anterioridad a la aprobación del Código, algunas instituciones habían aprobado los $\operatorname{suyos}^{61}$, mientras que otras lo hicieron con posterioridad $^{62}$.

Por su parte, una Decisión de la Comisión de 24 de febrero de 2010, aprobó su Reglamento interno, cuyo anexo contiene un Código de Buena Conducta Administrativa, para las relaciones de su personal con el público ${ }^{63}$.

\section{La transparencia en Internet}

Internet constituye un eficaz medio en materia de transparencia. Permite el acceso directo a los documentos con formato electrónico, existentes en las páginas web de las instituciones y órganos comunitarios, de modo que, el acceso es instantáneo. En el caso de documentos cuyo acceso no es directo, las instituciones disponen de registros de documentos. Una vez localizado el documento, se solicita de la institución pertinente. La web oficial de la Unión Europea facilita la localización de los documentos, al reunir el acceso a los registros de las instituciones y órganos. Asimismo dispone de modo independiente, de enlaces de acceso directo a documentos de instituciones, órganos, agencias y organismos descentralizados ${ }^{64}$.

La página del Consejo de la Unión Europea permite el acceso al registro de sus documentos, a excepción de los sensibles ${ }^{65}$. De modo directo a los documentos recientes, los relativos a las sesiones del Consejo a nivel ministerial, las órdenes del 
día de las reuniones de los órganos preparatorios del Consejo y los acuerdos ${ }^{66}$. Bajo la denominación "Transparencia legislativa", una sección permite el acceso a la información sobre las actividades del Consejo como órgano legislativo: calendarios y órdenes del día, relaciones mensuales de actos del Consejo y actas del mismo, reglamento interno y a los resultados de votaciones sobre actos legislativos ${ }^{67}$. Un enlace da acceso al procedimiento legislativo ordinario ${ }^{68}$, mientras que otro permite el seguimiento en directo de las sesiones públicas ${ }^{69}$. De otro lado, puede accederse a los actos legislativos del Consejo relativos a la transparencia, así como a los informes anuales y bianuales sobre acceso a documentos ${ }^{70}$.

Por su parte, la página del Parlamento Europeo permite acceder a su registro de documentos ${ }^{71}$. La Comisión Europea posibilita de un lado, el acceso a los libros blancos y verdes, estadísticas y encuestas ${ }^{72}$. De otro lado, permite la accesibilidad a los principales documentos, tales como los programas anuales de trabajo de la Comisión y sus anexos, iniciativas adoptadas y previstas por la misma e informes de síntesis anuales ${ }^{73}$. Por otra parte, puede accederse a un espacio de consultas abiertas, sobre iniciativas legislativas relativas a distintas políticas, de las que se ofrece la información pertinente. La participación se lleva a cabo mediante respuestas a un cuestionario $^{74}$.

El Consejo Europeo dispone de accesos a las conclusiones de la Presidencia ${ }^{75}$ y a los documentos presentados a dicha Institución ${ }^{76}$.

La página del Tribunal de Justicia denominada "Curia", contiene un repertorio de jurisprudencia, que de modo sistemático permite el acceso a los sumarios de las sentencias y autos del Tribunal de justicia, del Tribunal General y del Tribunal de la Función Pública ${ }^{77}$.

El Banco Central Europeo dispone de acceso a las publicaciones y estadísticas de la Institución $^{78}$. Por otra parte, a informes ${ }^{79}$ y notas de prensa ${ }^{80}$.

El Tribunal de Cuentas Europeo permite el acceso rápido a informes de fiscalización y dictámenes, informes especiales e informes anuales de actividad ${ }^{81}$. Por otro lado, a manuales y guías sobre auditorías ${ }^{82}$.

En la red puede consultarse la guía, Acceso a los documentos del Parlamento Europeo, del Consejo y de la Comisión. Contiene las instrucciones de acceso, además de la tramitación de solicitudes y recursos. Dispone también de un listado de direcciones de instituciones y órganos, relativas a la presentación de solicitudes de acceso y de recursos. Asimismo, contiene las direcciones de los registros de documentos de dichas instituciones así como, las correspondientes a los archivos, bibliotecas y centros de documentación ${ }^{83}$.

Destaca la guía, Fuentes de información de la Unión Europea y Organismos Internacionales, la cual ofrece un exhaustivo contenido en materia de redes de información europea, acceso a documentación de las instituciones ${ }^{84} \mathrm{y}$ bases de datos de la Unión Europea ${ }^{85}$. En otra parte, se ocupa del Consejo de Europa y de otras organizaciones internacionales.

El portal Eur-Lex permite el acceso al Diario oficial. Además contiene un apartado denominado "Colecciones", mediante el cual se accede a los Tratados y Acuerdos 
Internacionales, documentos preparatorios referidos a las fases del procedimiento legislativo o presupuestario, preguntas formuladas por los parlamentarios a la Comisión y al Consejo y jurisprudencia comunitaria ${ }^{86}$.

En junio de 2011, un Acuerdo interinstitucional entre el Parlamento y la Comisión, ha aprobado el Registro de Transparencia, para organizaciones y trabajadores autónomos, que participan en la elaboración y aplicación de las políticas de la Unión Europea $^{87}$. Su página web permite el acceso a los documentos oficiales relacionados con el mismo, a su Código de Conducta y demás asuntos relacionados con el Registro ${ }^{88}$.

\section{El Consejo de Europa}

Como organismo internacional de cooperación regional externo a la Unión Europea, destaca la labor del Consejo de Europa en materia de transparencia. Partimos de dos recomendaciones. La primera adoptada en $1981^{89}$, considera que el acceso del público a la información, refuerza su confianza en la administración y que debía asegurarse el acceso a la documentación en manos de las autoridades públicas.

Contiene una serie de principios, los cuales recomienda su adopción por los gobiernos de los Estados miembros: derecho de acceso a la información en poder de las autoridades públicas, distintas a los órganos legislativos y autoridades judiciales, provisión de medios para su ejercicio, no denegar el acceso en virtud de alegación de inexistencia de interés particular del solicitante, igualdad en el acceso a la información y restricciones limitadas a la protección de intereses públicos (seguridad nacional, orden público, bienestar económico del país, prevención de delitos y de divulgación de información confidencial), protección de la vida privada y de otros intereses privados legítimos. Asimismo, resolución de la solicitud de información en tiempo razonable, necesidad de motivar la denegación de las solicitudes y posibilidad de recurrir las resoluciones denegatorias del acceso.

La segunda recomendación fue adoptada en 200290. Considera entre otros aspectos, la importancia en una sociedad democrática, de una administración pública transparente y la disponibilidad de información sobre cuestiones de interés público. El acceso a los documentos ofrecía al público una visión de conjunto, que permitiría la formación de una opinión crítica sobre el estado de la sociedad y las autoridades, de modo que evitaba la corrupción.

Con carácter general, los principios sobre el ejercicio del derecho de acceso son similares a los anteriores. No obstante, define conceptos de autoridad pública y documentos públicos, prescribe el tratamiento de las demandas, determina los límites al ejercicio del derecho, formas de acceso, costes, procedimiento de revisión de solicitudes denegadas, medidas complementarias destinadas a garantizar el ejercicio del derecho de acceso, publicación y puesta a disposición a instancias de las autoridades públicas, de la información conservada por éstas, a fin de promover la transparencia de la administración, así como la participación del público en cuestiones de su interés.

En 2009 fue aprobado el Convenio $n^{\circ} 205$ sobre acceso a la documentación oficial ${ }^{91}$, abierto a la firma por los Estados miembros y adhesión por los Estados no miembros, 
inspirado en la Recomendación de 2002. Como expresa su preámbulo, dada la importancia de la transparencia de las autoridades públicas en las sociedades democráticas, el ejercicio del derecho de acceso a los documentos oficiales, constituye una fuente de información para el público, al que ayuda a configurar la opinión sobre el estado en que se encuentran la sociedad y las autoridades, al tiempo que fomenta la integridad, la eficiencia, la eficacia y la responsabilidad de dichas autoridades, lo que permite afirmar su legitimidad.

Declara la oficialidad de los documentos, a toda información registrada, elaborada o recibida y conservada por las autoridades públicas (Art. 1) ${ }^{92}$. Por tanto y según indica Guichot, “todos los documentos en poder de las autoridades son en principio públicos y solamente pueden ser retenidos para proteger otros derechos e intereses legítimos. A partir de ahí, diseña un mínimo estándar que, dejando un margen amplio a los Estados, constituye el mayor y más reciente esfuerzo de síntesis de los derechos estatales europeos" (Guichot, 2011 , p. 40).

Garantiza a todas las personas el acceso a los documentos, delimita las excepciones a dicho acceso y determina la no obligación de motivar las solicitudes de acceso ${ }^{93}$. En cuanto al procesamiento de las mismas, la autoridad debe prestar asesoramiento al solicitante en la identificación del documento en que esté interesado. Si el documento no se encuentra en poder de la autoridad pública, o no está autorizada para llevar a cabo el trámite, remitirá la solicitud a la autoridad competente. Las solicitudes deben ser atendidas con arreglo al principio de igualdad y resueltas con prontitud, dentro del plazo que previamente se hubiese especificado. Puede rechazarse una solicitud, si a pesar del asesoramiento de la autoridad pública, no permitiese la identificación del documento, o si fuese manifiestamente irrazonable. Las resoluciones denegatorias del acceso deberán ser motivadas.

El acceso a los documentos puede efectuarse mediante consulta del original o copia, o entrega de copia en diversos tipos de formato. En los casos de limitación parcial de acceso, debe facilitarse la consulta del resto con indicación de toda omisión. No obstante, puede denegarse en los casos en que a consecuencia de dicho límite, la versión parcial produjese engaño, careciera de sentido, o supusiera una carga irrazonable para la autoridad. Si el acceso solicitado se efectuase con facilidad, la autoridad puede remitir al solicitante a la correspondiente fuente de acceso (Arts. 2 a $6)$.

En los casos de denegación de solicitudes de acceso, el interesado podrá presentar reclamación ante un tribunal u otra institución independiente e imparcial, prevista en la legislación. El proceso de resolución deberá caracterizarse por su celeridad y gratuidad, además de que implique la reconsideración de la autoridad pública que hubiese denegado el acceso.

El Convenio establece una serie de medidas complementarias, destinadas a alcanzar los objetivos del mismo. Por un lado, la información al público sobre el ejercicio del derecho de acceso, modo de ejercitarlo, formación de las autoridades públicas sobre sus deberes respecto de la práctica del derecho de acceso, gestión eficaz de la documentación y observancia de los procedimientos de preservación y destrucción de documentos. Por otro lado, la publicación de documentos oficiales a iniciativa de las autoridades, a fin de promover la eficacia y la transparencia de las 
administraciones públicas, así como la participación del público en asuntos de interés general. A efectos de supervisión de la aplicación del Convenio, está prevista la creación de un grupo de especialistas sobre acceso a documentos oficiales, constituido por personas de reconocida competencia en la materia (Arts. 8 a 11).

El acceso a los documentos del Consejo de Europa puede efectuarse en la red, así como su archivo ${ }^{94}$.

\section{Conclusiones}

Finalizado este estudio, podemos llegar a las siguientes conclusiones:

Desde los inicios de la construcción europea, encontramos en los Tratados constitutivos manifestaciones relativas a la transparencia de las instituciones comunitarias. Con el tiempo, las disposiciones sobre transparencia fueron aplicándose a otras materias, como el medio ambiente.

La Declaración $n^{\circ} 17$ aneja al Acta final del Tratado de la Unión Europea firmado en Maastricht, constituye el punto de partida en materia de transparencia. El objeto de la Unión Europea consiste en obtener la confianza de las personas en las instituciones y órganos comunitarios. La celebración de sucesivos Consejos Europeos sentaron las bases de la política sobre la transparencia comunitaria.

Las instituciones alcanzaron acuerdos favorables a la transparencia de las mismas. Se aprobaron los Códigos de acceso a los documentos del Consejo y de la Comisión, cuyos principios inspiraron las normas vinculantes en dicha materia, que adoptaron otras instituciones, órganos y organismos comunitarios.

Destaca la labor del Defensor del Pueblo en la promoción de adopción de medidas, sobre acceso a la documentación pública, mediante la investigación y emisión de informes.

El Tratado de Amsterdam inaugura una nueva etapa en materia de transparencia, al introducir el principio de apertura en la toma de decisiones, así como al declarar el derecho de acceso a los documentos del Parlamento, del Consejo y de la Comisión, además de establecer los medios de impugnación frente a resoluciones denegatorias de solicitudes de acceso.

Las medidas consistieron en la accesibilidad a los documentos de las instituciones, órganos y organismos comunitarios, la transparencia de su funcionamiento y la claridad en la redacción de la legislación.

Mediante el Reglamento 1049/2001, las personas cuentan con un instrumento jurídico, que determina los beneficiarios del derecho de acceso a los documentos del Parlamento, del Consejo y de la Comisión, delimita las excepciones al ejercicio del mismo, establece el proceso de resolución de las solicitudes y los recursos frente a las resoluciones denegatorias del acceso. Sus principios se extendieron al resto de normas sobre transparencia, adoptadas por otros organismos comunitarios y los reglamentos internos de las instituciones.

El Tratado Constitucional dispuso los principios de democracia representativa y participativa, al tiempo que extendió el derecho de acceso a los documentos, además 
de a las instituciones, a órganos y organismos comunitarios. La no entrada en vigor del Tratado Constitucional, supuso que los principios establecidos en el mismo, fuesen adoptados por el Tratado de Lisboa.

La Carta de los Derechos Fundamentales de la Unión Europa, incluyó y elevo a dicho rango, al derecho de acceso a los documentos.

Los Códigos de Buena Conducta Administrativa, establecieron entre otros, los principios a observar por los funcionarios comunitarios en los procesos de solicitud de acceso a documentos.

El avance experimentado en las redes de comunicación informáticas, ha facilitado mediante Internet el ejercicio del derecho de acceso a la documentación y contribuido a una mayor transparencia.

El Consejo de Europa ha contribuido a la transparencia de las administraciones públicas, mediante iniciativas en materia de acceso a la documentación oficial en poder de las autoridades públicas.

\section{Notas}

1. Como indica Cotino, "el término más amplio y flexible de transparencia pública, incluye tanto el acceso a la información pública, cuanto otras querencias variadas inspiradas por un mismo principio: evitar el alejamiento de la Administración por opacidad, mostrar la apertura de la Administración a sus ciudadanos." Por otro lado señala que "la necesidad de la transparencia se agudiza conforme entidades supranacionales como la Unión Europea, adquieren mayores capacidades de gobierno, corriente que priva a los ciudadanos del conocimiento de lo que les es más próximo, se alejan quienes adoptan las decisiones políticas, abriendo a la indefinición dicho proceso.” En cuanto al acceso a la información pública, "permite comprobar la legitimación de hecho con que cuenta la Administración. De este modo, la transparencia pública es una garantía de la eficacia, eficiencia, objetividad, legalidad, de buena administración. En consecuencia, la transparencia está vinculada tanto a la participación democrática cuanto al control democrático, no sólo jurídico, sino también político de que la Administración persigue los fines que la justifican” (Cotino Hueso, 2002, pp. 4 y $6)$.

2. Las Instituciones de la Unión Europea están constituidas por el Parlamento Europeo, el Consejo Europeo, el Consejo, la Comisión Europea, el Tribunal de Justicia, el Banco Central Europeo y el Tribunal de Cuentas. (Véase el artículo 13. 1 del Tratado de la Unión Europea).

3. Véase el artículo 288 del Tratado de Funcionamiento de la Unión Europea.

4. Disponible en: http://eur-lex.europa.eu/es/treaties/index.htm\#founding > [Consulta: 25 de abril de 2012].

5. Artículo 5 del Tratado constitutivo de la Comunidad Europea del Carbón y del Acero: "La Comunidad cumplirá su misión, en las condiciones previstas en el presente Tratado, mediante intervenciones limitadas. A tal fin: orientará y facilitará la acción de los interesados, recogiendo información, organizando consultas y definiendo objetivos generales. (...) hará públicos los motivos de su acción y adoptará las medidas necesarias para el cumplimiento de las normas establecidas en el presente Tratado."

6. Véanse también los artículos 11, 125, 162, 163, 187 y 194 del Tratado constitutivo de la Comunidad Europea de la Energía Atómica. Asimismo, los artículos 15, 17, 25, 28 y 47 del Tratado constitutivo de la Comunidad Europea del Carbón y del Acero.

7. Véase el DO L, no 43, de 15 de febrero de 1983, pp. 1-3, (Reglamento) y pp. 14-15 (Decisión). Podían ser objeto de consulta los documentos, salvo excepciones, una vez transcurrido el plazo de treinta años desde su producción. En 2003, el Reglamento fue modificado por otro del Consejo, a fin de adaptarlo al Reglamento 1049/2001 del Parlamento Europeo y del Consejo, sobre acceso del 
público a los documentos del Parlamento, del Consejo y de la Comisión, en materia de clasificación de archivos, plazos de apertura al público de los documentos y exclusiones a la misma. Véase el DO L, $n^{\circ} 243$, de 27 de septiembre de 2003, pp. 1-4.

8. Directiva de 7 de junio en DO L, n ${ }^{\circ} 158$, de 23 de junio de 1990, pp. 56-58. Fue derogada por la Directiva del Parlamento Europeo y del Consejo de 28 de enero de 2003, relativa al acceso del público a la información medioambiental, en DO L, $\mathrm{n}^{\circ} 41$, de 14 de febrero de 2003, pp. 26-32. Por otra parte, la directiva del Parlamento Europeo y del Consejo de 26 de mayo de 2003, en DO L, $n^{\circ}$ 156, de 25 de junio de 2003, pp. 17-24, estableció medidas para la participación del público en la elaboración de planes y programas relacionados con el medio ambiente. De este modo se dotaba de transparencia al proceso decisorio.

9. Quedaban excluidos del derecho de acceso, los documentos cuya información afectase a expedientes relacionados con la confidencialidad de las deliberaciones de autoridades públicas; a las relaciones internacionales y a la defensa; a la seguridad pública; a documentos de investigación que contuviesen secretos comerciales e industriales; a los que afectasen a la confidencialidad de datos y de expedientes personales; a los datos aportados por terceros sin que estuviesen obligados a facilitarlos; a los que pudiesen influir de forma negativa en el medio ambiente. La resolución de las solicitudes de acceso debía efectuarse con prontitud y en todo caso, dentro del plazo de dos meses. En caso de resolución denegatoria del acceso solicitado, la cual había de motivarse, el interesado podía interponer recurso judicial o administrativo (Arts. 3 y 4 ).

10. España, Ley 38/1995, de 12 de diciembre sobre el derecho de acceso a la información en materia de medio ambiente, Boletín Oficial del Estado, 13 de diciembre de 1995, nº 297, pp. 35708-35710.

11. DO C, $\mathrm{n}^{\circ}$ 191, de 29 de julio de 1992, pp. 1-112. Asimismo, el DO C, nº 224, de 31 de agosto de 1992, pp. 1-130.

12. "El presente Tratado constituye una nueva etapa en el proceso creador de una Unión cada vez más estrecha entre los pueblos de Europa, en la cual las decisiones serán tomadas de la forma más próxima posible a los ciudadanos."

13. Las conclusiones del Consejo Europeo celebrado en Birmingham en octubre de 1992, contienen la declaración, "Una Comunidad cercana a sus ciudadanos". La Presidencia estimó necesaria la transparencia de la Comunidad "para garantizar un debate público mejor informado sobre sus actividades", así como la proximidad a los ciudadanos en la adopción de las decisiones. Al tiempo emplazaba a los ministros de asuntos exteriores, a que en el Consejo Europeo a celebrar en Edimburgo, presentasen iniciativas en favor de una mayor transparencia, de las actividades de las instituciones comunitarias, entre las que se encontraba la apertura al público de las deliberaciones del Consejo. Se mostró satisfecho por la oferta de la Comisión, de "ampliar aún más las consultas antes de proponer normativas.” Manifestó su deseo de alcanzar una legislación comunitaria "más simple y más clara.”(Véase el Boletín de las Comunidades Europeas nº 10-1992, pp. 9-10).

Las conclusiones sobre apertura y transparencia adoptadas por el Consejo Europeo de Edimburgo, de diciembre de 1992, consistieron en: 1. La mejora del acceso a los trabajos del Consejo, mediante debates abiertos sobre el programa de trabajo y cuestiones de interés comunitario. Asimismo, debates preliminares sobre propuestas legislativas importantes y publicación de las actas de votaciones en el Consejo. El acceso al público se efectuaría mediante transmisión televisada del debate en la sala de prensa del edificio del Consejo. 2. Información sobre el papel del Consejo, mediante la publicación completa de las conclusiones, redactadas de modo que fuesen comprensibles para el público. Mejora de la información sobre las decisiones del Consejo, cuyo informe anual de actividades debería ser atractivo e inteligible por el público, además de efectuarse un resumen con vistas a una mayor difusión. 3. Determinar las directrices que permitiesen incrementar la claridad y sencillez en la redacción de la legislación. Mejora del acceso a la legislación mediante su consolidación o codificación y de la base de datos CELEX, sobre documentación informatizada relativa al derecho comunitario. (Véase el Boletín de las Comunidades Europeas nº 12-1992, pp. 1921).

El Consejo Europeo celebrado en Copenhague en junio de 1993, instó al Consejo y a la Comisión, a que trabajasen en la línea de alcanzar un amplio derecho de acceso a la información. Disponible en: 
<www.consilium.europa.eu/uedocs/cms_data/docs/pressdata/es/ec/72925.pdf > [Consulta: 5 de mayo de 2012].

14. En 1993 destacan tres Comunicaciones de la Comisión. La primera, sobre mayor transparencia en el trabajo de la Comisión, (DO C, $\mathrm{n}^{\circ}$ 63, de 5 de marzo de 1993, pp. 8-10). Propuso una serie de medidas destinadas a incrementar la transparencia en el trabajo de dicha Institución: 1. Anticipar la aprobación del programa anual de trabajo de la Comisión. 2. Participación del Consejo de Ministros en la ejecución del programa legislativo interinstitucional, publicación y redacción de ambos programas en estilo más claro y accesible. 3. Participación pública en la preparación de decisiones y propuestas de la Comisión, redacción de la documentación en las lenguas oficiales y consolidación y codificación de la legislación. 4. Difusión de las bases de datos, como fuentes de información y celeridad en el acceso del público a los documentos.

La segunda Comunicación, relativa al acceso de los ciudadanos a los documentos de las instituciones, (DO C, $\mathrm{n}^{\circ} 156$, de 8 de junio de 1993, pp. 5-12). Consideraba que la mejora del acceso a la información, aumentaría la confianza de los ciudadanos en la Comunidad. Recogía los elementos principales del concepto de información: por un lado las medidas adoptadas por las autoridades al objeto de informar a los ciudadanos de sus actuaciones. Por otro lado, facilitar al ciudadano la información demandada. Estimaba que Estados miembros e Instituciones "deberían sumarse al principio de acceso a la información disponible” e invitaba al resto de éstas, a que desarrollasen dicho principio, para lo cual deberían definir las "normas elementales y requisitos mínimos.” Contiene los principios básicos a desarrollar por la Comisión: definición del concepto de documento, titularidad del derecho de acceso a la documentación, ausencia de motivación en la solicitud, plazo de resolución, excepciones y denegación motivada en forma expresa. Asimismo, contiene un estudio comparativo sobre políticas en materia de acceso a la información, en los Estados miembros y en algunos terceros países.

La tercera Comunicación de 2 de junio, sobre transparencia en la Comunidad (DO C, $\mathrm{n}^{\circ} 166$, de 17 de junio de 1993), pp. 4-10. La Comisión responde a la Declaración $n^{\circ} 17$ efectuada en Maastricht, relativa a la presentación de un informe sobre medidas de mejora de acceso del público a los documentos de las Instituciones, además de otras aplicables a sus relaciones con el público. Contiene los resultados obtenidos en la aplicación de las medidas sobre transparencia, grupos de interés, acceso a documentos, apertura y transparencia con el público.

Otras medidas consistieron en una resolución del Consejo, sobre calidad de la redacción de la legislación comunitaria, (DO C, nº 166, de 17 junio de 1993, p. 1).

En una declaración conjunta, adoptada con motivo de la Conferencia interinstitucional de Luxemburgo, el Consejo, el Parlamento Europeo y la Comisión, manifestaron el compromiso de alcanzar la transparencia. Además, expusieron las medidas adoptadas por cada Institución. Así, el Parlamento, la publicidad de las reuniones de sus comisiones y sesiones plenarias. En cuanto al Consejo, la publicidad de algunos debates y de los resultados motivados de las votaciones que tuviesen lugar en dicha Institución, así como las explicaciones de voto, mejora de la información sobre sus actividades y acceso a sus archivos. Por su parte, la Comisión dispuso entre otras: publicación de los programas de trabajo y legislativo, facilitar la accesibilidad del público a los documentos, mejora del conocimiento de las bases de datos y de transmisión de la información, publicación en las lenguas comunitarias y adopción de medidas dirigidas a facilitar la comprensión de los trabajos por el público. (Véase el Boletín de las Comunidades Europeas nº 10-1993, pp. 120122). Dicha declaración interinstitucional fue aprobada el 17 de noviembre de 1993 por el Parlamento. Véase el DO C, nº 329, de 6 de diciembre de 1993, pp. 132-133).

Por otra parte, cabe señalar un Acuerdo suscrito por el Consejo, la Comisión y el Parlamento, de 20 de diciembre de 1994, sobre adopción de un método de trabajo acelerado, dirigido a la codificación de la legislación (DO C, no 293, de 8 de noviembre de 1995, pp. 2-3). El texto fue sustituido por otro posterior, (DO C, $\mathrm{n}^{\circ} \mathrm{C} 102$, de 4 de abril de 1996, pp. 2-3). Véase también el Acuerdo de 28 de noviembre de 2001, para un recurso más estructurado a la técnica de la refundición de los actos jurídicos en DO C, n ${ }^{\circ} 77$, de 28 de marzo de 2002, pp. 1-3.

Por último, en 1995 y respecto de la transparencia, el Consejo dispuso la publicación sistemática de los resultados de las votaciones sobre actos legislativos; realizar un mayor número de debates retransmitidos sobre temas de interés comunitario; ofrecer informes a la prensa y al público con anterioridad a las sesiones; y encargar al Comité de Representantes Permanentes de los Gobiernos 
de los Estados miembros, el estudio de las condiciones en las que se pudiese permitir el acceso a las actas de las sesiones. Véase el Documento 7481/95, pp. 4-5.

15. DO L, n $\mathrm{n}^{\circ}$ 304, de 10 de diciembre de 1993, pp. 1-6. En relación con la transparencia, dispuso la retransmisión de los debates celebrados por el Consejo sobre orientación del programa semestral de trabajo de la Presidencia y en su caso, del programa anual de la Comisión (Art. 6); supuestos en que procedía la publicación de los resultados de las votaciones (Art. 7.5); y supuestos de acceso a los documentos (Art. 22). No se publicarían los resultados de votaciones que hubiesen dado como resultado votaciones indicativas o adopción de actos preparatorios. (Anexo).

16. Código de conducta relativo al acceso del público a los documentos del Consejo y de la Comisión en DO L, n 340, de 31 de diciembre de 1993, pp. 41-42. En 1995 fue aprobado por el Consejo un Código de conducta sobre publicación de las actas y de las declaraciones incluidas en las actas del Consejo, cuando hubiese actuado en calidad de legislador. Asimismo, tras la aprobación de las actas de sesiones y a efectos de idoneidad de su publicidad, el Consejo debía proceder al examen de los documentos que le hubiesen sido presentados, además de las decisiones y conclusiones adoptadas por dicha Institución. Véase el Documento 10204/95, pp. 15-16.

17. El Código dispuso dos tipos de solicitudes: iniciales y confirmatorias. Las primeras se efectuaban por escrito con suficiente claridad y debían contener los elementos precisos para la identificación del documento solicitado. En caso de que el autor de un documento poseído por la institución, fuese una persona física o jurídica, un Estado miembro, otra institución, órgano comunitario u organismo nacional o internacional, la solicitud debía dirigirse al mismo. El acceso se llevaba a cabo mediante consulta en el lugar donde se encontrase el documento o entrega de copia del mismo. La institución correspondiente podía impedir su reproducción y difusión con fines comerciales, mediante venta directa sin previa autorización. El plazo de resolución era de un mes. En caso de ser denegado el acceso, el solicitante podía presentar en idéntico plazo una solicitud confirmativa, a fin de que la institución revisase su decisión. De no presentarla, se entendía que renunciaba a la solicitud inicial. Al igual que en el caso anterior, el plazo de resolución de la solicitud era de un mes. Si el acceso era de nuevo denegado, la resolución debía motivarse e indicar los recursos de que disponía el solicitante, es decir, judicial y ante el Defensor del Pueblo Europeo.

18. Respecto del alcance de las excepciones, una sentencia del Tribunal de Primera Instancia, recordaba "que, cuando se establece un principio general y se prevén excepciones a dicho principio, estas últimas deben interpretarse y aplicarse restrictivamente, de modo que no se frustre la aplicación del principio general" (Apdo. 56). WWF/Comisión de las Comunidades Europeas, 5 de marzo de 1997 (C-105/95), Rec., 1997, p. II-313. Disponible en:<http://eur-lex.europa.eu/ LexUriServ/LexUriServ.do?uri=CELEX:61995TJ0105:ES:HTML> [Consulta: 10 de mayo de 2012].

19. Decisión del Consejo de 20 de diciembre de 1993 en DO L, nº 340, de 31 de diciembre de 1993, pp. 43-44.

20. Decisión de la Comisión de 8 de febrero de 1994 en DO L, nº 46, de 18 de febrero de 1994, pp. 5859. Una Comunicación de la Comisión sobre mejora de acceso de documentos, reiteraba las medidas de aplicación en las solicitudes de acceso contenidas en la Decisión, al tiempo que la completaba: define el concepto de documento y determina el estudio individual de cada solicitud. (Véase el DO C, nº 67, de 4 de marzo de 1994, pp. 5-6).

21. Entre otros, Banco Europeo de Inversiones, Normas de 26 de marzo de 1997, en DO C, nº 243, de 9 de agosto de 1997, pp. 13-15; Tribunal de Cuentas, Decisión de 7 de abril de 1997, en DO C, $n^{\circ}$ 295, de 23 de septiembre de 1998, pp. 1-2; Comité Económico y Social, Decisión de 27 de mayo de 1997, en DO L, $\mathrm{n}^{\circ}$ 339, de 10 de diciembre de 1997, p. 18; Instituto Monetario Europeo, Decisión de 3 de junio de 1997, en DO L, nº 90, de 25 de marzo de 1998, pp. 43-44; Parlamento Europeo, Decisión de 10 de julio de 1997, en DO L, n 263, de 25 de septiembre de 1997, pp. 27-29; Comité de las Regiones, Decisión de 17 de septiembre de 1997, en DO L, n 351, de 23 de diciembre de 1997, pp. 70-71; Fundación Europea para la Formación, Decisión de 27 de octubre de 1997, en DO C, $\mathrm{n}^{\circ}$ 369, de 6 de diciembre de 1997, pp. 10-11; Banco Central Europeo, Decisión de 3 de noviembre de 1998, en DO L, n ${ }^{\circ} 110$, de 28 de abril de 1999, pp. 30-32; y Fundación Europea para la Mejora de las Condiciones de Vida y de Trabajo, Decisión de 21 de noviembre de 1997, en DO L, n 296, de 17 de noviembre de 1999, pp. 25-26.

22. Una sentencia del Tribunal de Justicia Europeo, dispuso que mientras no se adoptasen normas generales sobre el derecho de acceso a los documentos de las instituciones comunitarias, éstas 
deberían adoptar medidas sobre la tramitación de las solicitudes (Apdo. 37). Países Bajos/Consejo de la Unión Europea, 30 de abril de 1996 (C-58/94), Rec., 1996, p. I-2169. Disponible en: <http:// eur-lex.europa.eu/LexUriServ/LexUriServ.do?uri=CELEX:6 1994CJ0058:ES:HTML> [Consulta: 17 de mayo de 2012].

23. DO C, $\mathrm{n}^{\circ} 44$, de 10 de febrero de 1998, pp. 9-13.

24. DO C, nº 292, de 21 de septiembre de 1998, pp. 170-173.

25. Véase el Documento 6423/1/98 REV 1. En 1999, una Decisión de 6 de diciembre, introdujo mejoras en la información de las actividades del Consejo y en el registro público de documentos. Consistieron por un lado, en el acceso al público de los puntos provisionales del orden de día de las sesiones del Consejo y de las reuniones de sus órganos preparatorios, en los casos en que el Consejo actuase en su capacidad legislativa. Por otro lado, dispuso la inclusión en el registro de documentos, de referencias al objeto y signatura de los documentos clasificados, excepto en los casos en que su divulgación pudiese menoscabar los intereses protegidos contemplados en la norma. Véase el DO L, n' 9 , de 13 de enero de 2000, pp. 22-23.

26. Véase el DO C, $\mathrm{n}^{\circ}$ 292, de 21 de septiembre de 1998, p. 172.

27. DO C, n $\mathrm{n}^{\circ}$ 73, de 17 de marzo de 1999, pp. 1-3. En 2003 se produjo un nuevo Acuerdo de 16 de diciembre. Reitera la aplicación del Acuerdo de 1998, garantiza la amplia difusión de los debates políticos, mediante la retransmisión por satélite y por Internet y aspira a la ampliación del acceso público a EUR-Lex. Asimismo, dicta normas sobre trasposición y aplicación del derecho comunitario, a la legislación de los Estados miembros, así como la simplificación y reducción del volumen de la legislación. Véase el DO C, nº 321 , de 31 de diciembre de 2003, pp. 1-5.

28. DO C, $\mathrm{n}^{\circ} 340$, de 10 de noviembre de 1997, pp. 1-308.

29. "El presente Tratado constituye una nueva etapa en el proceso creador de una Unión cada vez más estrecha entre los pueblos de Europa, en la cual las decisiones serán tomadas de la forma más abierta y próxima a los ciudadanos que sea posible."

30. Respecto de los reglamentos internos de las Instituciones, véanse los artículos 199 (Parlamento), 207.3 (Consejo) y 218.2 (Comisión).

31. El Parlamento Europeo se opuso "a que la noción del Consejo actuando en su capacidad legislativa ... pueda permitir en caso de legislación, una interpretación restrictiva del derecho de acceso y subraya que el Consejo no puede fijar de forma unilateral qué es lo que abarca esta legislación." Véase el DO C, nº 292, de 21 de septiembre de 1998, p. 172, apdo. 16.

32. La Decisión del Consejo del 9 de abril de 2001, cuyo fin era el aumento de la transparencia de las actividades del Consejo, dispuso la publicación de varias categorías de documentos: entre otros, órdenes del día provisionales de las sesiones del Consejo, de los Comités y grupos de trabajo, informes sobre el estado de los trabajos en el Consejo y varios tipos de notas y copias de cartas referidas a actos legislativos. Véase el DO L, n 111 , de 20 de abril de 2001, pp. 29-30.

33. Reglamento (CE) 1049/2001 de 30 de mayo de 2001 en DO L, n ${ }^{\circ}$ 145, de 31 de mayo de 2001, pp. 43-48.

34. Art. 3 a) "documento", todo contenido, sea cual fuere su soporte (escrito en versión papel o almacenado en forma electrónica, grabación sonora, visual o audiovisual) referentes a temas relativos a las políticas, acciones y decisiones que sean competencia de la institución."

35. Art. 9.1 "Se entenderá por documento sensible, todo documento que tenga su origen en las instituciones o en sus agencias, en los Estados miembros, en los terceros países o en organizaciones internacionales, clasificado como TRÈS SECRET/TOP SECRET, SECRET o CONFIDENTIEL, en virtud de las normas vigentes en la institución en cuestión, que protegen intereses esenciales de la Unión Europea o de uno o varios Estados miembros, en los ámbitos a que se refiere la letra a) del apartado 1 del artículo 4, en particular la seguridad pública, la defensa y los asuntos militares.” No obstante, Guichot indica que "el concepto de documentos sensibles que maneja el Reglamento 1049/2001, sólo coincide parcialmente con el sistema de clasificación de los documentos previstos en las normas de seguridad del Consejo y de la Comisión, lo que constituye, como reconoce la propia Comisión en su informe de 2004, una fuente potencial de incoherencias." (Guichot, 2011, pp. 150-151).

36. Una sentencia del Tribunal de Justicia dispuso que "una persona puede presentar una nueva solicitud de acceso a documentos a los que anteriormente se le había denegado. Tal solicitud obliga a la institución de que se trate, a examinar si la anterior denegación de acceso sigue estando justificada, habida cuenta de una modificación de la situación de hecho o de derecho acaecida en el 
ínterin” (Apdo. 57). Internationaler Hilfsfonds/Comisión Europea, 26 de enero de 2010 (C-362/08 P), Rec., 2010, p. I-669. Disponible en: http://eur-lex.europa.eu/LexUriServ/LexUriServ.do? uri=CELEX:62008CJ0362:ES:HTML [Consulta: 23 de mayo de 2012].

37. En la práctica y como indica Guichot, "las quejas ante el Defensor del Pueblo son escasas ( en torno a la decena de media anual) y acaban con una recomendación, primero, a la que la Institución concernida responde en un informe -en ocasiones, aceptando total o parcialmente la recomendación del Defensor de dar publicidad a los documentos solicitados, que se traslada al reclamante, para que haga alegaciones si la Institución no se acomoda plenamente a la recomendación, y, finalmente, en un dictamen del Defensor, en el que declara si ha habido o no mala administración- sin valor constrictivo. El número de recursos judiciales también es escaso respecto al volumen de solicitudes -lo cual ... es propio de este género de asuntos en que la gratuidad y la inmediatez son claves para la efectividad del derecho- . (Guichot, 2011, pp. 246-247).

38. La Decisión de 28 de noviembre de 2001 de la Mesa del Parlamento, dispuso la creación del registro de referencias. La tramitación y registro de solicitudes de acceso a documentos sensibles, se encuentran en el Título IV de la Decisión. Véase el DO C, n 374, de 29 de diciembre de 2001, pp. 1-6.

En opinión de Guichot, "la inclusión de un documento en el Registro no implica el derecho de acceso a los documentos. En efecto, por una parte, el hecho de que los documentos estén mencionados en el registro, no los hace automáticamente accesibles al público y, por otra parte, los documentos no recogidos en el registro podrán ser objeto de solicitudes de acceso, al igual que los que sí figuran en él.” (Guichot, 2011, p. 258).

39. Son: las propuestas de la Comisión; las posiciones comunes adoptadas por el Consejo en los procedimientos previstos en los artículos 251 y 252 del Tratado de la Comunidad Europea, con inclusión de sus exposiciones de motivos y las posiciones del Parlamento en dichos procedimientos; las decisiones marco, decisiones y convenios relativos a la cooperación policial y judicial en materia penal (artículo 34.2 del Tratado de la Unión Europea); los acuerdos internacionales celebrados en materia de política exterior y de seguridad común (artículo 24 del tratado de la Unión Europea); y los convenios firmados entre Estados, con arreglo al artículo 293 del Tratado de la Comunidad Europea.

40. Son: las iniciativas que presente al Consejo un Estado miembro con arreglo a lo dispuesto en el artículo 67. 1 del Tratado de la Comunidad Europea; las iniciativas y las posiciones comunes a que hace referencia el artículo 34.2 del Tratado de la Unión Europea; las directivas distintas a las contenidas en el artículo 254.1 y .2; y las decisiones distintas a las contenidas en el artículo 254. 1, las recomendaciones y los dictámenes.

41. Consejo, Decisión de 29 de noviembre de 2001 en DO L, n 313, de 30 de noviembre de 2001, pp. 40-43; Parlamento, Decisión de 13 de noviembre de 2002, en DO C, n ${ }^{\circ} 140 E$, de 13 de junio de 2002, p. 120; Comisión, Decisión de 5 de diciembre de 2001 en DO L, n 345, de 29 de diciembre de 2001, pp. 94-98; Autoridad Común de Control de Europol, Decisión de 26 de junio de 2006, en DO C, no 311 , de 19 de diciembre de 2006, pp. 13-14.

42. Declaración conjunta del Parlamento y del Consejo relativa al Reglamento 1049/2001, en DO L, $\mathrm{n}^{\circ}$ 173, de 27 de junio de 2001, p. 5. Así, la Decisión de 11 de febrero de 2003 del Comité de las Regiones en DO L, n ${ }^{\circ}$ 160, de 28 de junio de 2003, pp. 96-99. Esta Decisión sustituye a la de 17 de septiembre de 1997. Por otra parte, la modificación de los Reglamentos de organismos y agencias: Agencia Europea del Medio Ambiente, Autoridad Europea de Seguridad Alimentaria, Agencia Europea de Seguridad Aérea, Agencia Europea de Seguridad Marítima, Centro de Traducción de los Órganos de la Unión Europea, Agencia Europea de Reconstrucción, Agencia Europea para la Evaluación de los Medicamentos, Fundación Europea de Formación, Fundación Europea para la Mejora de las Condiciones de Vida y Trabajo; Reglamento relativo a la protección comunitaria de las obtenciones vegetales, para la aplicación del Reglamento 1049/2001 a la Oficina Comunitaria de Variedades Vegetales; Observatorio Europeo de las Drogas y las Toxicomanías, Observatorio Europeo del Racismo y la Xenofobia; Reglamento sobre la marca comunitaria, para la aplicación del Reglamento 1049/2001 a la Oficina de Armonización del Mercado Interior; Agencia Europea para la Seguridad y Salud en el Trabajo y el Centro Europeo para el Desarrollo de la Formación Profesional. Véase el DO L, no 245, de 29 de septiembre de 2003, pp. 1-43. Además, la Agencia de los Derechos Fundamentales de la Unión Europea, en virtud del Reglamento de 15 de febrero de 2007, en DO L, n ${ }^{\circ}$ 53, de 22 de febrero de 2007, pp. 1-14. 
43. Así, las normas adoptadas por el Comité de Dirección del Banco Europeo de Inversiones, en DO C, $\mathrm{n}^{\circ}$ 292, de 27 de noviembre de 2002, pp. 10-11. Esta disposición deroga la Decisión de 26 de marzo de 1997; la Decisión de 1 de julio de 2003 del Comité Económico y Social Europeo, en DO L, $n^{\circ}$ 205, de 14 de agosto de 2003, pp. 19-23. Esta Decisión anula la de 27 de mayo de 1997; el citado Reglamento del Consejo de 22 de septiembre de 2003, que modifica el Reglamento relativo a la apertura al público de los archivos históricos de la Comunidad Económica Europea y de la Comunidad Europea de la Energía Atómica, en DO L, n 243, de 27 de septiembre de 2003, pp. 1- 4; la Decisión del Banco Central Europeo de 4 de marzo de 2004 en DO L, nº 80, de 18 de marzo de 2004, pp. 42-44. Esta Decisión anula la de 3 de noviembre de 1998; la Decisión del Consejo de Administración de la Agencia Europea para la Seguridad y la Salud en el Trabajo, de 4 de marzo de 2004 en DO L, n ${ }^{\circ} 210$, de 11 de junio de 2004, pp. 1-3; la Decisión del Tribunal de Cuentas Europeo, de 10 de marzo de 2005, relativa al acceso del público a los documentos del Tribunal, en DO C, n 67, de 20 de marzo de 2009, pp. 1-4.

44. Disponible en: <www.consilium.europa.eu/uedocs/cms_data/docs/pressdata/es/ec/72639.pdf> [Consulta: 23 de mayo de 2012]. Así, En la fase inicial del procedimiento, correspondía la apertura al público de las propuestas legislativas en régimen de codecisión, por parte de la Comisión y de su debate. En la fase final, mediante la apertura de las votaciones y explicaciones de los votos. La publicidad se llevaría a cabo mediante retransmisión en directo de las deliberaciones del Consejo y del resultado de la votación, previa información al público de la fecha en que tuviere lugar la retransmisión. Véase, p. 25.

Una Decisión del Consejo de 22 de marzo de 2004, sobre aprobación de su reglamento interno, adoptó las directrices del Consejo Europeo de Sevilla. Véase el DO L, nº 106 de 15 de abril de 2004, pp. 22-45.

45. DO C, $\mathrm{n}^{\circ} 325$, de 24 de diciembre de 2002, pp. 1-184.

46. DO C, $\mathrm{n}^{\circ} 73$, de 25 de marzo de 2006, pp. 14-15.

47. Véase el Documento 10633/1/06 REV 1, Anexo I, pp. 23-24. Disponible en: <http:// register.consilium.europa.eu/pdf/es/o6/st10/st10633-re01.es06.pdf> [Consulta: 23 de mayo de 2012]. Así entre otras, insiste en la apertura al público de todas las deliberaciones del Consejo sobre adopción mediante codecisión, de actos legislativos; las votaciones y explicación del voto de los miembros del Consejo; extiende la apertura a las primeras deliberaciones del Consejo, en actos legislativos distintos a los adoptados mediante codecisión, que por su importancia hubiesen sido presentados de forma oral por la Comisión, en una sesión del Consejo; publicidad de las deliberaciones del Consejo de Asuntos Generales y Relaciones Exteriores sobre el programa de dieciocho meses, así como las deliberaciones sobre las prioridades del resto de formaciones del Consejo. Asimismo, la presentación del programa quinquenal de la Comisión, programa y estrategia política anual y sus debates.

48. DO C, $\mathrm{n}^{\circ} 310$, de 16 de diciembre de 2004, pp. 1-474.

49. DO C, n 306, de 17 de diciembre de 2007, pp. 1-229. Véanse las versiones consolidadas en DO C, $\mathrm{n}^{\mathrm{o}} 83$, de 30 de marzo de 2010, pp. 1-388.

50. Véase el DO L, n 325, de 11 de diciembre de 2009, pp. 35-61. Dispone los actos a publicar en el Diario oficial (Art. 17). El anexo II desarrolla los preceptos de consulta sobre documentos de terceros, determina las reglas a seguir en cuanto las peticiones de consulta de otras instituciones o de los Estados miembros, así como la tramitación de las solicitudes iniciales y confirmatorias (Arts. 2 a 8). Designa a la Secretaría General como la encargada de facilitar el acceso del público al registro de documentos del Consejo, dispone la inclusión en el registro de los documentos elaborados a partir del primero de julio de 2000, que se encontrasen a disposición del público. Dispone su publicación en Internet, con arreglo a las excepciones previstas en el Reglamento. Por último, designa los documentos directamente accesibles al público, cuyo acceso facilitaría la Secretaría General (Arts. 10 y 11).

51. DO L, n $\mathrm{n}^{\circ} 315$, de 2 de diciembre de 2009, pp. 51-55. Su artículo 10 dispone la aplicación a sus documentos, de las disposiciones previstas en el anexo II del Reglamento interno del Consejo, cuya aplicación se efectúa mutatis mutandis.

52. Carta de los Derechos Fundamentales de la Unión Europea, de 7 de diciembre de 2000 en DO C, $n^{\circ}$ 364 , de 18 de diciembre de 2000 , pp. 1-22. 
53. Carta de los Derechos Fundamentales de la Unión Europea, de 12 de diciembre de 2007, en DO C, $\mathrm{n}^{\mathrm{o}} 303$, de 14 de diciembre de 2007, pp. 1-16. Asimismo, véase el DO C, n 83, de 30 de marzo de 2010 , pp. 389-403.

54. Véase el documento A4-0190/97. Disponible en: <www.europarl.europa.eu/sides/getDoc.do? type $=$ REPORT\&reference $=$ A4-1997-0190\&language $=\mathrm{ES}>$ [Consulta: 15 de mayo de 2012].

55. Resolución del Parlamento Europeo de 16 de julio de 1998, en DO C, nº 292, de 21 de septiembre de 1998, pp. 170-173, (Apdo. 6).

56. Véase el DO C, $\mathrm{n}^{\circ} 219$, de 30 de julio de 1999, pp. 456-458, (Apdo. 7).

57. El Defensor del Pueblo Europeo definió el concepto de mala administración, la cual se producía "cuando un organismo público no obra de conformidad con las normas o principios a que ha de atenerse obligatoriamente.” (Defensor del Pueblo Europeo, 1998, p. 25).

58. Véase la Resolución del Parlamento Europeo de 6 de julio de 2000, sobre el Informe Anual del Defensor del Pueblo Europeo en 1999, en DO C, n 121, de 24 de abril de 2001, pp. 468-470, (Apdo. C).

59. Disponible

en:

$<$ https://docs.google.com/viewer? $\mathrm{a}=\mathrm{v} \& \mathrm{q}=$ cache:qk_6qrmayxAJ:www.ombudsman.europa.eu/shortcuts/document.faces/es/3806/ pdf.bookmark $+\mathrm{c} \% \mathrm{C} 3 \%$

B3digo + de + buena + conducta + administrativa + julio $+1999 \&$ hl=es\&gl=es\&pid=bl\&srcid=ADGEES g_9PbsxGom--

R2dsY22zZ935WwvIjprUxruii5fkvWfvfs4PHuUKsVlsWrw96b3_SBiAcjfOhGkcd2hY9ibkwelH GN8-

ErQ19xJFBge2pFSkZzLvOXBWC7uxro1MjoU_JlrLV\&sig=AHIEtbQ1u7isy88WF3ZYQOVRnE g5N62Y3g > [Consulta: 15 de mayo de 2012].

60. Resolución del Parlamento Europeo de 6 de septiembre de 2001, en DO C, $\mathrm{n}^{\circ} 72 \mathrm{E}$, de 21 de marzo de 2002, pp. 331-336. El texto se encuentra disponible en: < www.ombudsman.europa.eu/es/ resources/code.faces> [Consulta: 15 de mayo de 2012].

61. Entre otros, el Centro de Traducción de los órganos de la Unión Europea, Decisión de 10 de febrero de 2000, disponible en: <http://cdt.europa.eu/CDT\%20Documents/Code\%20of\% 20Good\%20Administrative\%2oBehaviour/code_es.pdf $>$ [Consulta: 15 de mayo de 2012]; la Fundación Europea para la Mejora de las Condiciones de Vida y Trabajo, Decisión de 11 de febrero de 2000, en DO L, n ${ }^{\circ}$ 316, de 15 de diciembre de 2000, pp. 69-73; el Tribunal de Cuentas Europeo, Decisión de 19 de junio de 2000, disponible en: <https://docs.google.com/viewer? $\mathrm{a}=\mathrm{v} \& \mathrm{q}=$ cache:KDF 5akhTFHIJ:www.lapiedad.org.ar/base/archivos2005/Codigo\%2520de\% 2520Buena\%2520Conducta\%2520Administrativa\%2520del\%2520Personal\%2520del\%

2520Tribunal\%2520de\%2520Cuentas\%

2520Europeo.doc+Decision+de+19+de+junio +de+2000+c\%C3\%

B3digo+de+buena+conducta+administrativa\&hl=es\&gl=es\&pid=bl\&srcid=ADGEESj8OY3mtnn d2yzlK_w7rxCyTsdX80Bz5okY5Mb5akCNL-1e89Or5wW_DnItBIA9bcbyyDaL3mrsfpvItoMDZuJfvWuckuotTXYF9FGxdo8XKZDS1sp_MtYMcE1xNhG5oX bT9ld\&sig=AHIEtbTb_QzEgFAJDtQ1OgoI3dyfT1GF4g> [Consulta: 15 de mayo de 2012]; la Comisión, Decisión de 17 de octubre de 2000, por la que se modifica su reglamento interno. Anexo, en DO L, n 267, de 20 de octubre de 2000, pp. 63-66; el Banco Europeo de Inversiones, en DO C, $\mathrm{n}^{\mathrm{o}} 17$, de 19 de enero de 2001, pp. 26-27; y la Secretaría General del Consejo, Decisión de 25 de junio de 2001, en DO C, $\mathrm{n}^{\circ}$ 189, de 5 de julio de 2001, pp. 1-4.

62. Centro Europeo para el desarrollo de la Formación Profesional, Decisión de 22 de junio de 2011 , en DO C, $\mathrm{n}^{\circ} 285$, de 29 de septiembre de 2011 , pp. 3-7.

63. Véase el DO L, $\mathrm{n}^{\circ} 55$, de 5 de marzo de 2010, pp. 60-67.

64. Disponible en <http://europa.eu/documentation/official-docs/index_es.htm> [Consulta: 19 de julio de 2012].

65. Disponible en: <www.consilium.europa.eu/documents/access-to-council-documents-publicregister?lang $=\mathrm{es}>$ [Consulta: 19 de julio de 2012].

66. Disponible en: < www.consilium.europa.eu/documents?lang=es $>$ [Consulta: 19 de julio de 2012$]$.

67. Disponible en: <www.consilium.europa.eu/documents/legislative-transparency?lang=es> [Consulta: 19 de julio de 2012].

68. Disponible en: <http://www.consilium.europa.eu/policies/ordinary-legislative-procedure? lang $=\mathrm{es}>$ [Consulta: 19 de julio de 2012]. 
69. Disponible en: <www.consilium.europa.eu/council/open-sessions?lang=es/> [Consulta: 19 de julio de 2012].

70. Disponible en: < http://ue.eu.int/documents/policy-regarding-access-to-council-documents/basic -texts-on-transparency?lang=es/> [Consulta: 19 de julio de 2012].

71. Disponible en: <www.europarl.europa.eu/RegistreWeb/search/simple.htm?language $=\mathrm{ES}>$ [Consulta: 19 de julio de 2012].

72. Disponible en: <http://ec.europa.eu/about/index_es.htm> [Consulta: 19 de julio de 2012].

73. Disponible en: <http://ec.europa.eu/atwork/key-documents/index_es.htm> [Consulta: 19 de julio de 2012].

74. Disponible en: <http://ec.europa.eu/yourvoice/consultations/index_es.htm> [Consulta: 19 de julio de 2012].

75. Disponible en: <www.european-council.europa.eu/council-meetings/conclusions.aspx?lang=es > [Consulta: 19 de julio de 2012].

76. Disponible en: <www.european-council.europa.eu/council-meetings/documents-submitted-to-theeuropean-council.aspx?lang=es $>$ [Consulta: 19 de julio de 2012].

77. Disponible en: <http://curia.europa.eu/jcms/jcms/Jo2_7046/> [Consulta: 19 de julio de 2012].

78. Disponible en: <www.ecb.int/pub/html/index.en.html/> [Consulta: 19 de julio de 2012$]$.

79. Disponible en: <www.ecb.int/ecb/orga/governance/html/index.en.html/> [Consulta: 19 de julio de 2012].

80. Disponible en: <www.ecb.int/press/pr/date/2004/html/pro40318.en.html > Consulta: 19 de julio de 2012].

81. Disponible en: <http://eca.europa.eu/portal/page/portal/eca_main_pages/home> Consulta: 19 de julio de 2012 ].

82. Disponible en: < http://eca.europa.eu/portal/page/portal/audit/Audit\%2Odocuments> [Consulta: 19 de julio de 2012].

83. Disponible en: <www.europarl.europa.eu/RegData/PDF/Guide_ES.pdf> [Consulta: 19 de julio de 2012].

84. Diario oficial de la Unión Europea, documentos COM, SEC, CES, CDR, libros verdes y libros blancos, Boletín de la Unión Europea, fichas de síntesis legislativas, fichas técnicas de la Unión Europea, documentos del Parlamento, de la Comisión, del Consejo de la Unión Europea, del Consejo Europeo, de los tribunales de Justicia, General y de la Función Pública, del Comité de las Regiones, del Comité Económico y Social, y del Banco Central Europeo.

El Diario oficial de la Unión Europea se clasifica varias series: L (legislación); C (Comunicaciones e informes); C A (Desarrolla el capítulo de comunicaciones e informes); C E (Contiene los textos preparatorios de actos legislativos); y S (Suplemento al Diario oficial que contiene anuncios de contratos en diversos sectores). Los documentos COM, emitidos por la Comisión, contienen la evolución de las propuestas legislativas de la Comisión, con anterioridad a su redacción en el Diario oficial. Los documentos SEC, emitidos por la Secretaría General de la Comisión, son de carácter interno, cuyo contenido relaciona la labor de la Comisión con el Consejo u otra institución a la que se dirija el documento. Los documentos CES contienen los dictámenes del Comité Económico y Social, sobre propuestas legislativas de la Comisión, en las que el Comité puede expresar su opinión, pudiendo incluir informes sobre las actividades propias del Comité. Asimismo, los documentos CDR del Comité de las Regiones. Los libros verdes, publicados por la Comisión, tienen por objeto el establecer debates entre los ciudadanos, fuera del marco institucional de la Unión Europea, sobre temas concretos. La participación ciudadana se efectúa través de una página web, que recoge los comentarios y propuestas. Los libros blancos recogen los datos obtenidos tras la consulta ciudadana. (Ramón Reyero y Luengo Rodríguez, 2011, pp. 33-47.)

85. Eur-Lex, Pre-Lex, N-Lex, Eu Law, Oeil, Curia y Eurostat. La base Eur-Lex recoge datos sobre legislación y jurisprudencia. Pre-Lex describe los procesos legislativos, desde los documentos COM hasta su publicación en el Diario Oficial. N-Lex contiene las bases de datos oficiales de las legislaciones nacionales de 23 Estados miembros. Eu Law contiene la trasposición de las directivas al ordenamiento interno de los Estados miembros. Oeil permite conocer con antelación, los trabajos de las sesiones plenarias del Parlamento, los documentos COM y SEC de los últimos siete días para su lectura en el Parlamento, así como la legislación en la que se encuentra trabajando, agrupada por temas. La base Curia corresponde al Tribunal de Justicia y al Tribunal General. Un enlace permite la consulta de la jurisprudencia de dichos tribunales y asuntos de la Función Pública. Por último, 
Eurostat contiene los datos de los Institutos Nacionales de Estadística de los Estados miembros, así como de la European Free Trade Association. (Ramón Reyero y Luengo Rodríguez, 2011, pp. 49-74.)

86. Disponible en: <http://eur-lex.europa.eu/es/index.htm> [Consulta: 19 de julio de 2012$]$.

87. DO L, n ${ }^{\circ} 191$, de 22 de julio de 2011, pp. 29-38.

88. Disponible en: <http://europa.eu/transparency-register/index_es.htm> [Consulta: 19 de julio de 2012].

89. Recomendación del Consejo de Europa de 25 de noviembre de 1981, R (81) 19. Disponible en: $<$ https://wcd.coe.int/com.instranet.InstraServlet? command $=$ com.instranet.CmdBlobGet $\&$ InstranetImage $=600643 \&$ SecMode $=1 \&$ DocId $=673734 \& \mathrm{U}$ sage $=2>$ [Consulta: 22 de julio de 2012].

90. Recomendación del Consejo de Europa de 21 de febrero de 2002, Rec (2002) 2. Disponible en: $<$ https://wcd.coe.int/ViewDoc.jsp?id=262125\&Site=CM> [Consulta: 22 de julio de 2012$]$.

91. Disponible en: <www.access-info.org/documents/Access_Docs/Advancing/Council_of_Europe/ Convention_on_Access_to_Official_Documetnts_CofE._es.pdf> [Consulta: 22 de julio de 2012].

92. Por autoridades públicas se refiere a "1) el gobierno y administración a nivel nacional, regional y local; 2) los organismos legislativos y autoridades judiciales, en cuanto realizan funciones administrativas según la normativa nacional propia; 3) las personas naturales o jurídicas cuando ejercen como una autoridad administrativa." No obstante, "cada parte, a la hora de la firma o al depositar su instrumento de ratificación, aceptación, aprobación o adhesión, mediante una declaración enviada al Secretario General del Consejo de Europa, puede declarar que la definición de “autoridades públicas" también incluye a una o más de las siguientes: 1) organismos legislativos en lo que concierne al resto de sus actividades; 2) autoridades judiciales en lo que concierne al resto de sus actividades; 3) personas naturales o jurídicas que realizan funciones públicas o actúan financiadas con fondos públicos, según la normativa nacional propia” (Art. 12 2) a) i-ii).

93. "Cada Parte garantizará el derecho de cualquiera, sin discriminación de ningún tipo, a acceder, bajo petición, a los documentos públicos en posesión de las autoridades públicas” (Art. 2 1)

"Cada Parte puede limitar el derecho del acceso a los documentos públicos. Los límites deberán estar previstos por una ley, ser necesarios en una sociedad democrática y tener como objetivo la protección de: la seguridad nacional, la defensa y relaciones internacionales; la seguridad pública; la prevención, la investigación y el procesamiento de actividades criminales; las investigaciones disciplinarias; la inspección, control y supervisión por autoridades públicas; la intimidad y otros intereses privados legítimos; los intereses económicos y comerciales; las políticas estatales de cambio de moneda, monetarias y económicas; la igualdad de las partes en los procedimientos judiciales y la administración eficaz de la justicia; el medio ambiente y las deliberaciones dentro o entre las autoridades públicas en lo referente al examen en un asunto. Los Estados interesados, a la hora de la firma o al depositar su instrumento de ratificación, aceptación, aprobación o adhesión, mediante una declaración enviada al Secretario General del Consejo de Europa, pueden declarar que las comunicaciones oficiales con la Familia Real y su Casa Real o el Jefe de Estado también están incluidas entre las posibles limitaciones." No obstante, el acceso a un documento puede denegarse si fuese susceptible de perjudicar los intereses protegidos, a excepción de que exista un interés público superior. Por otra parte, las partes pueden determinar el plazo de aplicación de los límites indicados (Art. 3).

94. Disponible en: <www.coe.int/t/dgal/dit/ilcd/Doc/Online_en.asp> [Consulta: 22 de julio de 2012].

\section{Bibliografía}

Cerrillo i Martínez, A. (1998), La transparencia administrativa: Unión Europea y medio ambiente, Tirant lo Blanch, Valencia.

Cotino Hueso, L. (2002), “Transparencia y derecho a la información pública en la Unión Europea. ¿De valor en alza a derecho fundamental?”, comunicación presentada en IV Jornadas Internacionales sobre derechos y libertades fundamentales. (Los derechos fundamentales en la Unión Europea). 7-8 Noviembre, Zaragoza. Disponible en: http://www.unizar.es/derecho/doctorado_humanos/cotinohueso 11.doc [Consulta: 8 de julio de 2012]. 
MEI, II, Vol. 3, nº 5, pág. 203

Defensor del Pueblo Europeo (1997), Informe Anual 1996. Oficina de Publicaciones Oficiales de las Comunidades Europeas, Luxemburgo.

Defensor del Pueblo Europeo (1998), Informe Anual 1997. Oficina de Publicaciones Oficiales de las Comunidades Europeas, Luxemburgo.

Defensor del Pueblo Europeo (2000), Informe Especial relativo a la investigación sobre la existencia y el acceso público a un código de buena conducta administrativa en las instituciones y órganos comunitarios. Disponible en:

http://www.ombudsman.europa.eu/es/cases/specialreport.faces/es/407/html.bookmark\#_ftn3 [Consulta: 15 de mayo de 2012].

Guichot, E. (2011), Transparencia y acceso a la información en el derecho europeo, Derecho Global, Sevilla.

Ramón Reyero, E. y Luengo Rodríguez, B. (2011), Fuentes de información de la Unión Europea y Organismos Internacionales. Disponible en:

http://ec.europa.eu/spain/pdf/fuentes-informacion-ue-y-oi-vs-web_es.pdf

[Consulta: 8 de julio de 2012].

Tomás Mallén, B. (2004), El derecho fundamental a una buena administración, Instituto Nacional de Administración Pública, Madrid.

Unión Europea, (2002), Acceso a los documentos del Parlamento Europeo, del Consejo y de la Comisión, Oficina de Publicaciones Oficiales de las Comunidades Europeas, Bélgica. 